\title{
Hypertonicity Sensing in Organum Vasculosum Lamina Terminalis Neurons: A Mechanical Process Involving TRPV1 But Not TRPV4
}

\author{
Sorana Ciura, ${ }^{1}$ Wolfgang Liedtke, ${ }^{2}$ and Charles W. Bourque ${ }^{1}$ \\ ${ }^{1}$ Center for Research in Neuroscience, Research Institute of the McGill University Health Centre, Montreal General Hospital, Montreal, Quebec H3G 1A4, \\ Canada and ${ }^{2}$ Center for Translational Neuroscience, Duke University Medical Center, Durham, North Carolina 27710
}

Primary osmosensory neurons in the mouse organum vasculosum lamina terminalis (OVLT) transduce hypertonicity via the activation of nonselective cation channels that cause membrane depolarization and increased action potential discharge, and this effect is absent in mice lacking expression of the transient receptor potential vanilloid 1 (Trpv1) gene (Ciura and Bourque, 2006). However other experiments have indicated that channels encoded by Trpv4 also contribute to central osmosensation in mice (Liedtke and Friedman, 2003; Mizuno et al., 2003). At present, the mechanism by which hypertonicity modulates cation channels in OVLT neurons is unknown, and it remains unclear whether $\operatorname{Tr} p v 1$ and $\operatorname{Trpv} 4$ both contribute to this process. Here, we show that physical shrinking is necessary and sufficient to mediate hypertonicity sensing in OVLT neurons isolated from adult mice. Steps coupling progressive decreases in cell volume to increased neuronal activity were quantitatively equivalent whether shrinking was evoked by osmotic pressure or mechanical aspiration. Finally, modulation of OVLT neurons by tonicity or mechanical stimulation was unaffected by deletion of trpv4 but was abolished in cells lacking Trpv1 or wild-type neurons treated with the TRPV1 antagonist SB366791. Thus, hypertonicity sensing is a mechanical process requiring $\operatorname{Tr} p v 1$, but not $\operatorname{Tr} p v 4$.

\section{Introduction}

A continuous monitoring of blood solute concentration is essential for body fluid homeostasis and for the dynamic defense of the body's osmotic set point (Bourque, 2008). In mammals, the primary osmosensory neurons mediating this task are located in the brain's organum vasculosum lamina terminalis (OVLT) (Thrasher et al., 1982; Ramsay et al., 1983; Johnson and Gross, 1993). Studies in rodents have shown that the rate of action potential discharge in osmosensitive OVLT neurons rises proportionally with extracellular fluid osmolality (Sayer et al., 1984; Honda et al., 1990; Vivas et al., 1990; Ciura and Bourque, 2006). Information encoded by this activity is relayed synaptically to effector nuclei to induce autonomic (Brooks et al., 2005), behavioral (Hollis et al., 2008), and neuroendocrine responses (Richard and Bourque, 1995; Trudel and Bourque, 2010) that maintain fluid homeostasis.

The excitatory effects of hypertonicity on OVLT neurons persist during synaptic blockade (Vivas et al., 1990). Moreover,

\footnotetext{
Received March 21, 2011; revised Aug. 14, 2011; accepted Aug. 19, 2011.

Author contributions:S.C. and C.W.B. designed research;S.C. performed research; W.L. contributed unpublished reagents/analytic tools; S.C. analyzed data; S.C. and C.W.B. wrote the paper.

This work was supported by Canadian Institutes of Health Research Operating Grants MOP-9939 and MOP-82818 to C.W.B. and by Duke University start-up funds and support from the Klingenstein Foundation (New York, NY) to W.L. The Research Institute of the McGill University Health Center is supported by the Fonds de la Recherche en santé du Québec. S.C. was recipient of a Canada Graduate Scholarship and C.W.B. holds a James McGill Professor Chair. The authors declare no competing financial interests.

Correspondence should be addressed to Charles W. Bourque, Room L7-216, Montreal General Hospital, 1650 Cedar Avenue, Montreal, QC H3G 1A4, Canada. E-mail: charles.bourque@mcgill.ca.

DOI:10.1523/JNEUROSCI.1420-11.2011

Copyright $\odot 2011$ the authors $\quad 0270-6474 / 11 / 3114669-08 \$ 15.00 / 0$
}

experiments on OVLT neurons acutely isolated from adult mice have shown that hyperosmotic stimuli excite these cells via activation of nonselective cation channels causing membrane depolarization (Ciura and Bourque, 2006). These observations indicate that OVLT neurons can transduce osmotic perturbations through a cell-autonomous process, but the mechanism mediating the osmotic modulation of channel activity in these cells remains unknown. Acute extracellular hypertonicity causes water efflux from cells to equalize osmotic forces and therefore provokes increases in intracellular solute concentration and decreases in cell volume. Since many types of ion channels are regulated by specific solutes (e.g., Cukkemane et al., 2011) or ionic strength (e.g., Nilius et al., 2000), osmosensing could in principle be mediated by osmotically induced changes in solute concentration. Alternately, OVLT neurons might detect hypertonicity through a mechanical effect linked to shrinking, as observed in neurohypophysial neurons of the supraoptic nucleus (Zhang et al., 2007). Clarification of the cellular mechanism responsible for hypertonicity sensing in OVLT neurons is a prerequisite for our understanding of the molecular architecture and function of the mammalian osmoreceptor.

Previous studies have shown that members of the transient receptor potential vanilloid (TRPV) family of cation channels are strong candidates for the molecular detection of osmotic stimuli (Liedtke, 2007). Moreover, we have shown previously that hypertonicity-induced excitation is absent in OVLT neurons isolated from mice genetically engineered to lack the transient receptor potential vanilloid 1 ( $\operatorname{Tr} p v 1)$ gene (Ciura and Bourque, 2006). However the conclusion that Trpv1 encodes an osmore- 
ceptor channel was recently challenged because hypertonicityinduced expression of the immediate early gene Fos is maintained in the OVLT of mice lacking the gene (Taylor et al., 2008). Moreover, previous studies have indicated that another member of the TRPV gene family, $\operatorname{Tr} p v 4$, is strongly expressed in the OVLT (Liedtke et al., 2000), and deletion of Trpv4 in mice attenuates Fos expression and osmoregulatory responses in vivo (Liedtke and Friedman, 2003; McHugh et al., 2010; Lechner et al., 2011). In this study we therefore examined the cellular basis for hypertonicity sensing in mouse OVLT neurons and determined whether this process requires expression of both Trpv1 and Trpv4.

\section{Materials and Methods}

Animals. All experiments performed in this study were performed at the Center for Research in Neuroscience of the Research Institute of McGill University Health Centre (Montreal, Canada) and followed a protocol approved by the Animal Care Committee of McGill University (protocol \#1190). The animals used were males and females of adult age (2-12 months) and consisted of wild-type (WT) C57BL mice (Charles River Laboratories), Trpv1 ${ }^{-1-}$ mice (Birder et al., 2002; obtained from The Jackson Laboratory), or $\operatorname{Tr} p v 4^{-/-}$mice (Liedtke and Friedman, 2003).

Preparation of isolated neurons. Acutely isolated OVLT neurons were obtained as described previously (Ciura and Bourque, 2006). Briefly, mice anesthetized with halothane were killed by decapitation and brains were quickly removed and placed in cold $\left(4^{\circ} \mathrm{C}\right)$ oxygenated PIPES solution, $\mathrm{pH}$ 7.3, comprising $120 \mathrm{~mm} \mathrm{NaCl}, 5 \mathrm{~mm} \mathrm{KCl}, 1 \mathrm{~mm} \mathrm{MgCl}$, $20 \mathrm{~mm}$ PIPES, $1 \mathrm{~mm} \mathrm{CaCl}_{2}$, and $10 \mathrm{~mm}$ D-glucose (all from Sigma). Blocks of tissue $\left(<1 \mathrm{~mm}^{3}\right)$ containing the OVLT were then removed and incubated in PIPES solution containing $5 \mathrm{mg} / \mathrm{ml}$ protease X and XIV (Sigma) at room temperature for $30 \mathrm{~min}$, after which they were washed in enzyme-free PIPES solution where they were kept for $0.5-4 \mathrm{~h}$. Individual tissue blocks in PIPES solution $(\sim 0.4 \mathrm{ml})$ were triturated and the resulting suspension was plated onto 5-6 $30 \mathrm{~mm}$ Petri dishes (BD Falcon). Cells were then perfused with HEPES solution consisting of $150 \mathrm{~mm}$ $\mathrm{NaCl}, 3 \mathrm{~mm} \mathrm{KCl}, 1 \mathrm{~mm} \mathrm{MgCl}_{2}, 10 \mathrm{~mm}$ HEPES, and $10 \mathrm{~mm}$ glucose and mannitol to adjust the osmolality of the solution to $312 \mathrm{mosmol} / \mathrm{kg}$ (isotonic) or higher, as required. Every effort was made to restrict the size of the tissue block to the expected midline position of the OVLT, located rostral and dorsal to the preoptic recess of the third ventricle. However, it is likely that some of the tissue surrounding the OVLT was also included in most of our dissections. Interestingly, the fraction of isolated neurons showing cell-autonomous osmosensory responses in these preparations $(\sim 61 \%)$ is quite similar to the proportion of neurons showing osmosensory properties when recording from the OVLT in hypothalamic explants ( $\sim 63 \%$; Ciura and Bourque, 2006). Thus neurons isolated from the area of the OVLT using this procedure appear to be representative of their physiological properties in situ.

Volume measurements. Normalized volume (nVol; relative to baseline) was quantified from measurements of maximal cross-sectional area (CSA; total number of pixels) of cells in digitized images using Scion Image for Windows 4.02 (Scion). All values of CSA measured in the control period were averaged $\left(\mathrm{CSA}_{\mathrm{o}}\right)$, and values of $\mathrm{nVol}$ at individual time points $\left(\mathrm{nVol}_{t}\right)$ were calculated from the CSA value at corresponding time point $\left(\mathrm{CSA}_{t}\right)$ using the following equation: $\mathrm{nVol}_{t}=\left[\left(\mathrm{CSA}_{t}\right)^{1.5} /\right.$ $\left(\mathrm{CSA}_{\mathrm{o}}\right)^{1.5}$ ]

Whole-cell recording. Cells were recorded at room temperature using an Axopatch-1D amplifier (Molecular Devices) in the whole-cell configuration using pipettes pulled on a P-97 puller (Sutter Instruments) and filled with an internal solution comprising $120 \mathrm{~mm}$ K-gluconate, $1 \mathrm{~mm}$ $\mathrm{MgCl}_{2}$, 1 mм EGTA, 4 mм Na -ATP, $1 \mathrm{~mm} \mathrm{Na-GTP,} 14$ mм phosphocreatine, $10 \mathrm{~mm}$ HEPES (5-8 M $\Omega$, pH 7.34; osmolality adjusted to 290 $\mathrm{mosmol} / \mathrm{kg}$ using mannitol). In the voltage-clamp experiments, $0.5 \mu \mathrm{M}$ tetrodotoxin (Sigma) was added to the HEPES solution. Where indicated, SB366791 (Sigma) was added as a 1:5000 dilution from a stock of $15 \mathrm{~mm}$ (in DMSO) to a final concentration of $3 \mu \mathrm{M}$. Where indicated, Ruthenium red (RuR) (Sigma) was added at a final concentration of 10
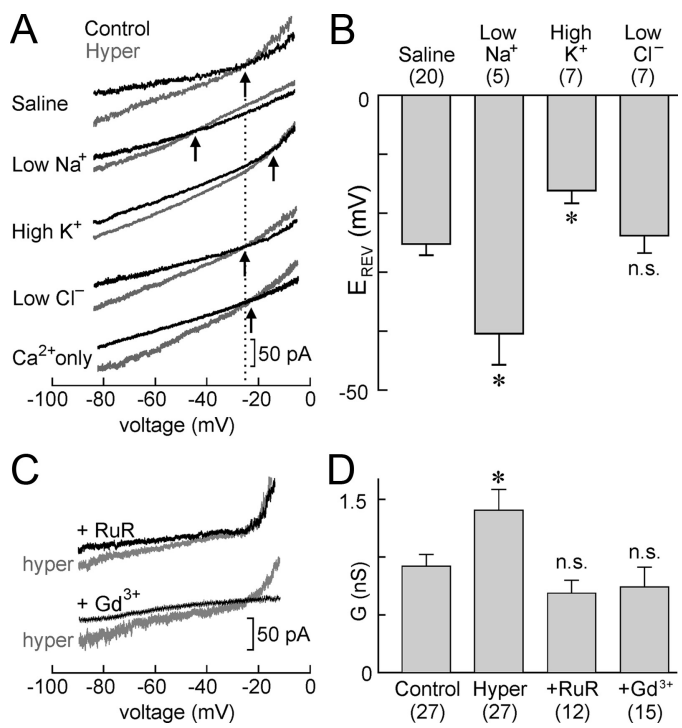

Figure 1. Hypertonicity activates calcium-permeable cation channels in OVLT neurons. $A, I-V$ relations taken under control (black) and hyperosmotic conditions ( $g r a y ;+25$ mm mannitol) illustrate the effects of changing the ionic composition of the extracellular solution on the reversal potential, $E_{\text {rev }}$ of the osmotically induced current. Arrows indicate the $E_{\text {rev }}$ observed in specific experiments relative to the mean value measured in saline (dotted line). $\boldsymbol{B}$, Bargraphs show themean ( $\pm \mathrm{SEM}) E_{\mathrm{rev}}$ values measured under different conditions. $C, I-V$ relations taken in the presence of a hyperosmotic stimulus (black traces; $+25 \mathrm{~mm}$ mannitol) and following addition of RuR $(10 \mathrm{~mm})$ or gadolinium $\left(\mathrm{Gd}^{3+}, 300 \mu \mathrm{M}\right) . \boldsymbol{D}$, Mean ( \pm SEM) changes in membrane conductance induced by hypertonicity in the absence (control) or presence of RuR and $G d^{3+}{ }^{*} p<0.05$ vs control; n.s., not significant).

$\mu \mathrm{M}$. For the ion substitution experiments the solutions were as follows. For "low $\mathrm{Na}^{+}$" the external solution contained $50 \mathrm{~mm} \mathrm{NaCl}, 3 \mathrm{~mm} \mathrm{KCl}$, $1 \mathrm{~mm} \mathrm{MgCl}_{2}, 10 \mathrm{~mm}$ HEPES, and $10 \mathrm{~mm}$ glucose. For the "High $\mathrm{K}^{+}$" the external solutions consisted of $150 \mathrm{~mm} \mathrm{NaCl}, 6 \mathrm{~mm} \mathrm{KCl}, 1 \mathrm{~mm} \mathrm{MgCl}_{2}, 10$ mM HEPES, and $10 \mathrm{~mm}$ glucose. The "low $\mathrm{Cl}^{-"}$ experiment was performed with an external solution comprising $100 \mathrm{~mm}$ Na-gluconate, 50 mM NaCl, $1 \mathrm{~mm} \mathrm{MgCl}, 3 \mathrm{~mm} \mathrm{KCl}, 10 \mathrm{~mm}$ HEPES, and $10 \mathrm{~mm}$ glucose. For " $\mathrm{Ca}^{2+}$ only" experiment the internal solution contained $130 \mathrm{~mm}$ $\mathrm{CsCl}, 10 \mathrm{~mm} \mathrm{NaCl}, 1 \mathrm{~mm}$ EGTA, $0.1 \mathrm{~mm} \mathrm{CaCl}_{2}$, and $10 \mathrm{~mm}$ HEPES, pH 7.25 , and the external solution comprised $70 \mathrm{mM} \mathrm{CaCl}_{2}, 6 \mathrm{mM} \mathrm{Ca}(\mathrm{OH})_{2}$, $10 \mathrm{~mm}$ glucose, and $20 \mathrm{~mm}$ HEPES, pH 7.25.

In all experiments, pipette pressure was recorded via a digital manometer (model PMO-15D, World Precision Instruments) connected in parallel to the pipette holder. Mechanical changes in cell volume were induced by imposing slow and gradual changes in pipette pressure $( \pm 30$ $\mathrm{mmHg}$ ) via an air-filled syringe until effects on cell volume or electrical responses were qualitatively observed. Quantification of volume changes was done off-line after the experiments.

Changes in solution were applied by rapidly switching the fluid delivery tube facing the cell using a piezoelectric stepper device (SF-77B; Warner Instruments). Steady-state current-voltage ( $I-V)$ relations were obtained by commanding slow voltage ramps $(25 \mathrm{mV} / \mathrm{s})$ from -100 to 0 $\mathrm{mV}$. Membrane conductance $(G)$ was determined from the slope of the $I-V$ relation between -80 and $-50 \mathrm{mV}$. All cells showing unstable baseline values of $\mathrm{nVol}, \mathrm{G}$, or holding current were excluded from the analysis. Also excluded from the analysis were cells with resting values of $G$ lying below $0.2 \mathrm{nS}$ (an arbitrary value below which very low noise levels and small capacitance transients suggested incomplete whole-cell access) or above $2 \mathrm{nS}$ (an arbitrary value above which cells or seals were presumed to be damaged). As mentioned above, $\sim 62 \%$ of OVLT neurons show functional responses to osmotic stimulation, whereas the rest are nonresponsive (Ciura and Bourque, 2006). The analysis of electrophysiological experiments related to transduction (see Figs. 1-6) was therefore restricted to cells showing measurable responses. For the comparative analysis of responses recorded from different genotypes and in the presence of SB366791 (Fig. 7), all cells recorded were included and larger populations were used. 

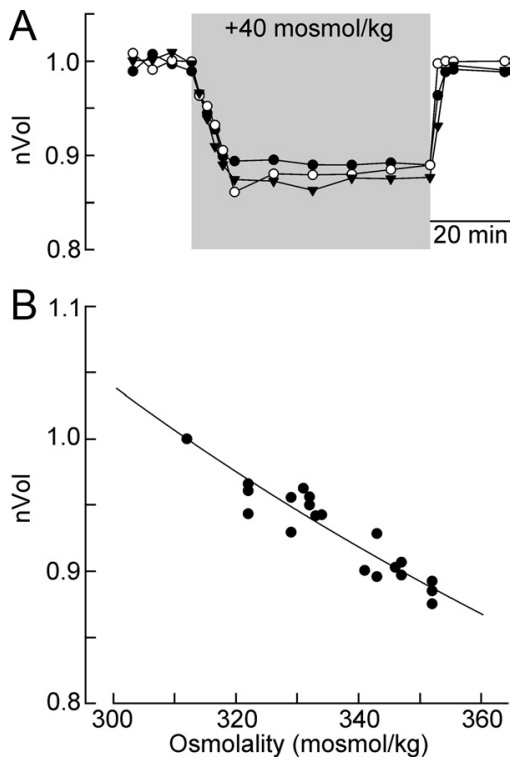

Figure 2. Osmometry in OVLT neurons. A, Time course of normalized volume changes ( $\mathrm{nVol}$, relative to baseline) observed in three isolated mouse OVLT neurons exposed to a 60 min hyperosmotic stimulus ( $+40 \mathrm{mosmol} / \mathrm{kg}$; excess mannitol). $\boldsymbol{B}$, Steady-state values of $\mathrm{nVol}$ observed in different isolated OVLT neurons exposed to various external osmolalities $(n=19)$. The solid line is the best fit through the data points using the Boyle-van't Hoff equation; $\mathrm{nVol}=b+$ $(a \times(1-b) / \pi)$, where $\pi$ is the test osmolality, $a$ is the set point $(312 \mathrm{mosmol} / \mathrm{kg})$, and $b$ is the osmotically inactive fraction of the cell volume $(0.01 \pm 0.03) ; r^{2}=0.955$.

\section{Results}

Hypertonicity activates a calcium-permeable cation current The hypothesis that hypertonicity activates a calcium-permeable nonselective cation channel in mouse OVLT neurons has not been verified experimentally. We therefore examined the effects of hypertonicity ( $+25 \mathrm{mosmol} / \mathrm{kg}$; excess mannitol) on $I-V$ relations measured in solutions of different ionic composition. As found previously (Ciura and Bourque, 2006), hypertonicity consistently increased the slope of steady-state $I-V$ relations (i.e., membrane conductance), confirming that ion channels are opened by this stimulus. As shown in Figure $1, A$ and $B$, the reversal potential $\left(E_{\text {rev }}\right)$ of the current was significantly more negative in solution containing low $\left[\mathrm{Na}^{+}\right]\left(E_{\mathrm{rev}}:-40.5 \pm 5.2 \mathrm{mV}\right.$, $n=5$ in low $\left[\mathrm{Na}^{+}\right]$vs $-25.3 \pm 1.9 \mathrm{mV}$ in control solution, $n=$ $20, p=0.003)$ and depolarized in solutions containing high $\left[\mathrm{K}^{+}\right]$ $\left(E_{\mathrm{rev}}:-16.0 \pm 1.9 \mathrm{mV}, n=7, p=0.01 \mathrm{vs}\right.$ control) but was unaffected by reducing $\left[\mathrm{Cl}^{-}\right]\left(E_{\mathrm{rev}}:-23.9 \pm 2.4 \mathrm{mV}, n=7\right.$ in low $\left[\mathrm{Cl}^{-}\right], p=0.7$ vs control). Increases in $I-V$ slope were also observed when mannitol was added to an external solution comprising only $\mathrm{Ca}^{2+}$ as a charge-carrying cation (control, $0.66 \pm$ $0.32 \mathrm{nS}$; hypertonic, $2.06 \pm 0.60 \mathrm{nS}, n=5, p=0.01$; Fig. $1 A, B$ ). Moreover, as illustrated in Figure 1, $C, D$, responses recorded in normal saline were reversed by addition of the nonspecific cation channel inhibitor $\mathrm{Gd}^{3+}$ (300 $\mu \mathrm{M}, n=15, p=0.429$ vs control, one-way AVOVA/ Student-Newman-Keuls test) or by the broad spectrum Trp channel inhibitor RuR $(10 \mu \mathrm{M}, n=12, p=0.603)$. These results indicate that isolated mouse OVLT neurons re-

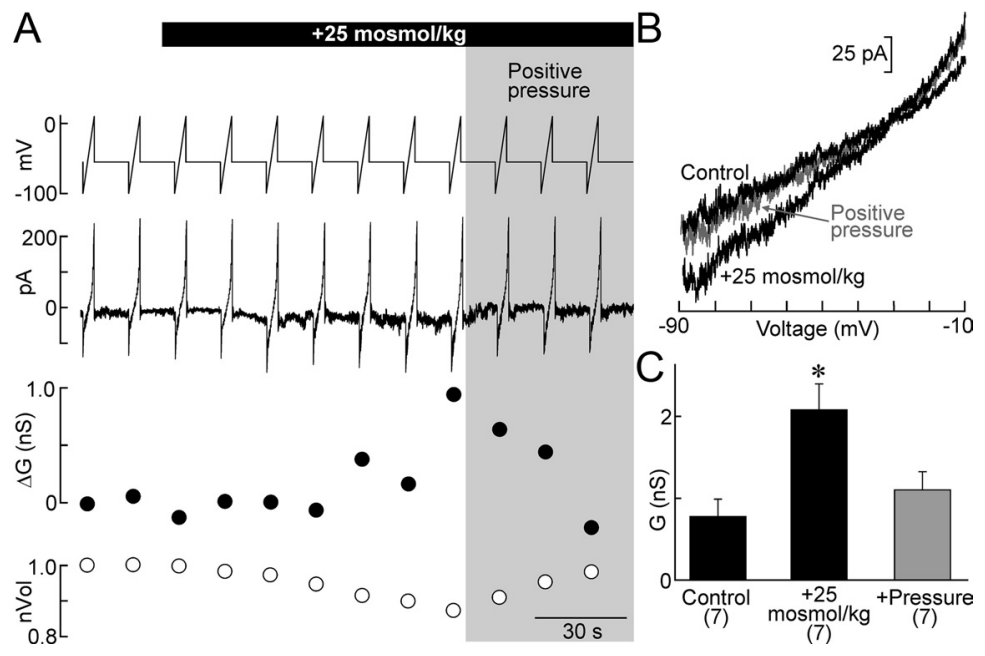

Figure 3. Hypertonicity sensing does not involve a concentrating effect. $A$, Example of the voltage command (top trace) and the current response (bottom trace) of an OVLT neuron under whole-cell voltage-clamp conditions during the application of a hypertonic stimulus (black bar) and positive pressure to the recording electrode (gray shading). Graphs below these traces plot changes in membrane conductance $(\Delta G)$ and normalized volume (nVol) observed during this experiment. $\boldsymbol{B}$, Current-voltage relations measured during the experiment shown in $\boldsymbol{A}$ during control (black trace), hypertonicityinduced shrinking, and after restoring cell volume with positive pressure (gray). C, Bar graphs show the mean ( \pm SEM) membrane conductance measured from seven cells recorded in the three conditions $\left({ }^{*} p<0.05\right)$.

spond to hypertonic stimuli by the activation of RuR-sensitive nonselective cation channels that are permeable to $\mathrm{Na}^{+}, \mathrm{K}^{+}$, and $\mathrm{Ca}^{2+}$.

\section{Hypertonicity sensing requires cell shrinking}

Many types of cells oppose hypertonicityinduced shrinking through mechanisms that mediate a regulatory volume increase (Strange, 2004; Lang, 2007). While this process can confer protection against osmotic damage to cells, it would also negate the value of shrinking as a useful signal for osmosensory detection. Interestingly, previous work has shown that other types of osmosensory neurons can behave as osmometers (Zhang and Bourque, 2003). However, it remains unknown whether this is also the case for primary osmoreceptor neurons in the OVLT. To address this issue, we examined the effects of hypertonicity on the volume of neurons acutely isolated from the OVLT of adult mice. As illustrated in Figure $2 \mathrm{~A}$, hypertonic stimuli induced reversible decreases in cell volume that could be sustained for

Statistics. All values in this study are reported as mean plus or minus the standard error of the mean ( \pm SEM.). Curve fits were performed using Sigmaplot 10 (Systat Software). Statistical differences between mean values were evaluated using (as appropriate) an ANOVA or repeated-measures ANOVA followed by the Tukey or Student-Newman-Keuls tests for multiple comparisons or a Student's one-tailed or paired $t$ test (as appropriate) using Sigmastat 2.03 software (Systat). Comparisons of linear regression parameters were performed using Prism 5 software (GraphPad Software). Differences between values were considered to be significant when $p<0.05$. as long as $60 \mathrm{~min}$. Indeed, an analysis of the data using one-way repeated-measures ANOVA indicated that the volume decreases observed 10 (to $87.6 \pm 1.6 \%$ of control) and 60 min after the onset of the stimulus $(88.5 \pm 0.8 \%$ of control $)$ were significantly different from control $(p<0.001)$ but not from each other $(p=$ 0.577; Tukey test for multiple comparisons, $n=3$ ). Moreover steady-state volume ( $\mathrm{nVol}$, normalized to baseline) varied as an inverse function of osmolality (Fig. $2 B ; n=19$ cells), as predicted 

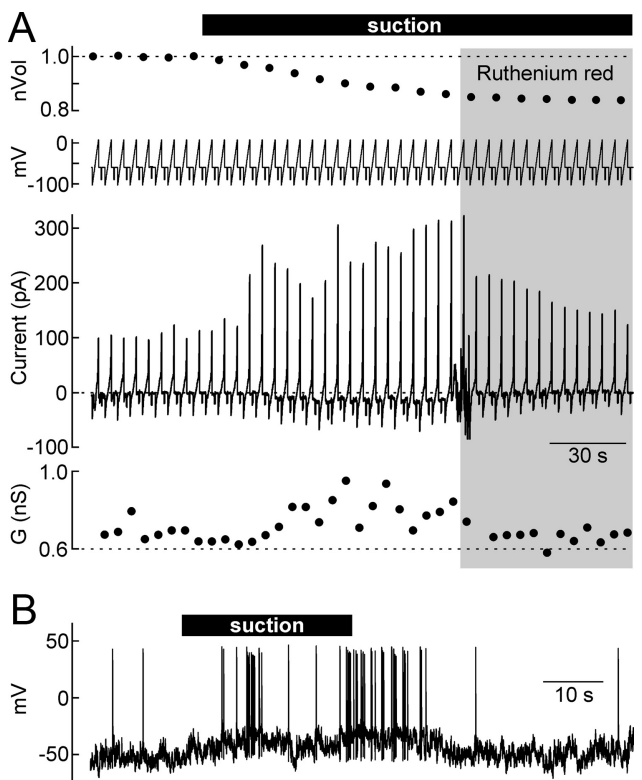

Figure 4. Cellular shrinking activates OVLT neurons. $A$, Effects of suction $(-10 \mathrm{mmHg}$, black bar) and addition of $10 \mu \mathrm{m}$ Ruthenium red (gray area) on an isolated OVLT neuron. Panels respectively plot normalized volume $(\mathrm{nVol})$, voltage command $\left(\mathrm{mV} ; V_{\text {Hold }},-60 \mathrm{mV}\right)$, membrane current, and input conductance $(G)$. The voltage commands, repeated every $5 \mathrm{~s}$, consisted of a slow voltage ramp $(-100$ to $+10 \mathrm{mV}, 2.5 \mathrm{~s})$ followed by a $-30 \mathrm{mV}$ pulse $(250 \mathrm{~ms})$. Dashed lines are visual references at $1.0 \mathrm{nVol}, 0 \mathrm{pA}$, and $0.6 \mathrm{nS}$. $B$, Effects of suction $(-10 \mathrm{mmHg})$ on whole-cell voltage recorded under current-clamp conditions.

by the Boyle-van't Hoff equation (Zhang and Bourque, 2003). Hypertonicity-mediated activation of cation channels in OVLT neurons could therefore result either from an intracellular concentration effect or from the mechanical effect of cell shrinking.

To determine whether a concentrating effect is sufficient to mediate channel activation, we examined whether hypertonicityinduced increases in membrane conductance were maintained when cell volume was restored by intracellular injection of a small amount of artificial intracellular medium. As shown in Figure 3, $A$ and $B$, hypertonic stimulation ( $+25 \mathrm{mosmol} / \mathrm{kg}$ ) caused a progressive reduction in $\mathrm{nVol}$ along with an increase in membrane conductance and generation of an inward transduction current $\left(I_{\mathrm{T}}\right)$ at the holding potential $\left(\mathrm{V}_{\text {Hold }} ;-60 \mathrm{mV}\right)$. A small amount of positive pressure was then applied to the inside of the recording pipette to restore cell volume in the continued presence of the hyperosmotic stimulus. This procedure caused $n$ Vol to return toward baseline and was accompanied by a concurrent reduction of membrane conductance and $I_{\mathrm{T}}$ (Fig. $3 A, B$ ). In experiments performed on seven cells, the hypertonicity-induced increase in conductance (control, $0.78 \pm 0.21 \mathrm{nS}$; hypertonic, $2.08 \pm 0.31$ $\mathrm{nS} ; p=0.004$ ) was eliminated upon pressure-induced inflation $(1.10 \pm 0.22 \mathrm{nS}, p=0.06$; Fig. $3 C$ ).

To determine whether shrinking alone is sufficient to excite OVLT neurons, we then examined the impact of reducing cell volume by applying negative pressure (suction) to the inside of the recording pipette under constant (isotonic) conditions. Application of suction $(-10$ to $-25 \mathrm{mmHg}$ ) to 15 cells tested under voltage clamp caused significant decreases in $\mathrm{nVol}$ accompanied by increases in $I_{\mathrm{T}}$ and conductance (control, $0.31 \pm 0.06 \mathrm{nS}$; suction, $0.78 \pm 0.12 \mathrm{nS} ; p=0.0001$; e.g., Fig. $4 A$ ). In agreement with these observations, cells tested under current-clamp conditions showed suction-induced membrane depolarization $(+17.73 \pm 1.90$ $\mathrm{mV}, p=0.0007)$ and increased firing rate $(+10.24 \pm 3.16 \mathrm{~Hz}$, $n=7, p=0.03$; e.g., Fig. $4 B$ ). Although some of the OVLT
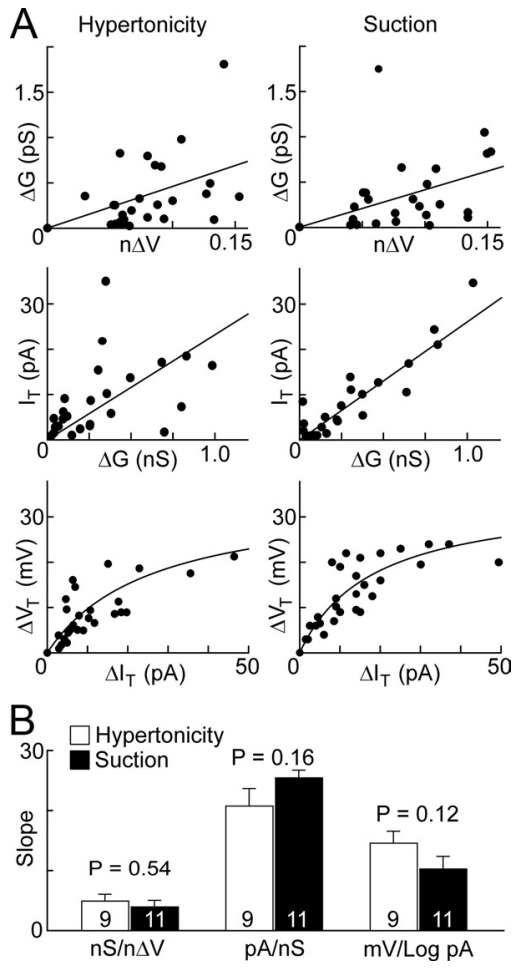

Figure 5. Shrinking-evoked transduction is equivalent during hypertonicity and suction. $A$, Scatter plots show correlations between consecutive steps linking cell shrinking $(n \Delta V)$ to membrane conductance change $(\Delta G)$, transduction current $\left(I_{T}\right)$, and depolarizing transduction voltage $\left(\Delta V_{\mathrm{T}}\right)$ in neurons exposed to hypertonicity (left; $n=9$ ) or pipette suction (right; $n=11$ ). Solid lines are best fits of the data. $\boldsymbol{B}$, Bar graphs compare the slopes of linear regressions ( \pm SEM) through all pairs of datasets ( $p$ values are indicated above each pair).

neurons tested were able to recover spontaneously from the effects of negative pressure (i.e., when pipette pressure was returned to zero, $n=6$; e.g., Fig. $4 B$ ), other cells displayed irreversible suction-evoked shrinking and sustained increases in membrane current and conductance. However, in such cases the electrophysiological responses could be inhibited by bath application of $10 \mu \mathrm{M}$ ruthenium red (inhibition $=87.7 \pm 4.0 \%, n=$ $11, p<0.001$; e.g., Fig. $4 A$ ), consistent with the involvement of shrinking-activated TRPV channels.

\section{Hypertonicity sensing is a mechanical process}

To determine whether the mechanical effect of shrinking can fully account for hypertonicity sensing, we performed a quantitative comparison of the consecutive steps linking cell shrinking to firing rate during hyperosmotic stimulation and suction in different subsets of isolated OVLT neurons. Steady-state $I-V$ relations and corresponding images acquired at regular intervals (5-20 s) were used to measure values of membrane conductance, $I_{\mathrm{T}}$ and $\mathrm{nVol}$, at different time points before and after the onset of the stimuli. We first examined the relation between changes in membrane conductance ( $\Delta G$, relative to baseline) and normalized shrinking $(\mathrm{n} \Delta \mathrm{V}$, defined as $1-\mathrm{nVol})$. As illustrated by the top panels in Figure $5 A, \Delta G$ increased in proportion with $\mathrm{n} \Delta \mathrm{V}$ whether volume was reduced by hypertonicity ( $n=9$ cells) or suction ( $n=11$ cells). Statistical analysis (Fig. $5 B$ ) revealed that the slopes of linear regressions fitted through both datasets were not significantly different from each other (hypertonicity, $4.90 \pm$ $1.15 \mathrm{nS} / \mathrm{n} \Delta \mathrm{V}$, vs suction, $3.93 \pm 1.10 \mathrm{nS} / n \Delta \mathrm{V} ; p=0.542)$. We next examined how the magnitude of $I_{\mathrm{T}}$ related to values of $\Delta G$ during both forms of stimulation. As shown by the middle panels 

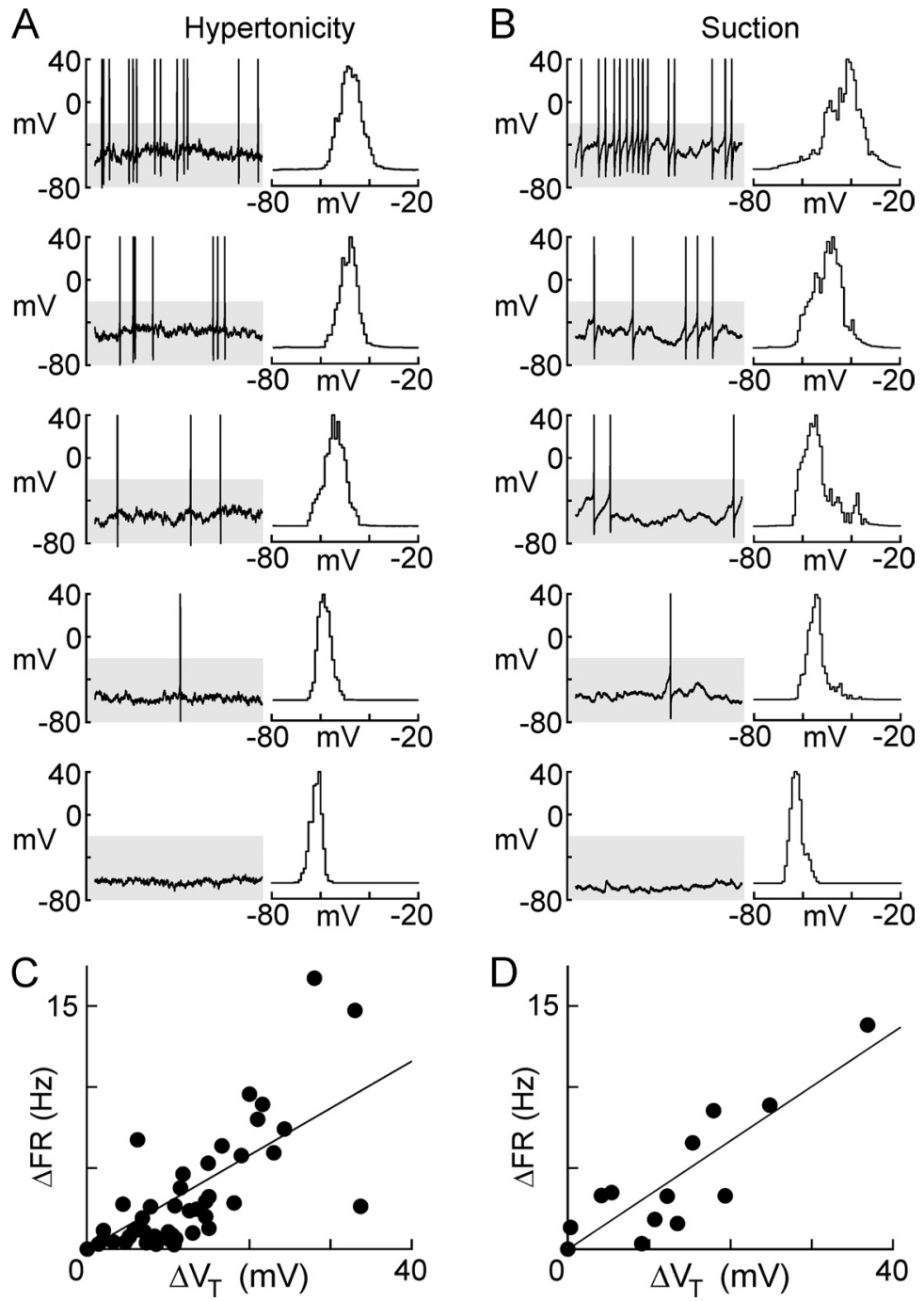

Figure 6. Depolarization-evoked excitation is equivalent during hypertonicity and suction. $\boldsymbol{A}$, Panels on the left show representative excerpts $(3 \mathrm{~s}$ ) of whole-cell voltage recorded at different times during the onset of the excitatory effect of a hyperosmotic stimulus (control is at the bottom and maximum excitatory effect is at the top). Panels at right show normalized all-points distributions of membrane voltage recorded from the shaded areas of corresponding excepts. $\boldsymbol{B}$, The progressive excitatory effects of suction measured in another OVLT neuron is shown using the same layout as $\boldsymbol{A}$. C, Plot showing the relation between osmotically induced change in membrane voltage $\left(\Delta V_{\mathrm{T}}\right)$ and change in action potential firing rate ( $\left.\Delta \mathrm{FR}\right)$ observed in a group of $100 \mathrm{VLT}$ neurons. The solid line is a linear regression through the data. $D$, Equivalent plot showing the relation between $\Delta V_{\mathrm{T}}$ and $\Delta F R$ during suction-induced excitation in four OVLT neurons.

in Figure $5 A$, the absolute amplitude of $I_{\mathrm{T}}$ was linearly related to values of $\Delta G$, and the slopes of linear regressions through both groups were not significantly different from one another (osmotic, $20.8 \pm 2.9 \mathrm{pA} / \mathrm{nS}$, vs mechanical, $25.5 \pm 1.3 \mathrm{pA} / \mathrm{nS}, p=$ 0.16; Fig. $5 B$ ).

We then examined the impact of changes in $I_{\mathrm{T}}$ on the amplitude of the depolarizing receptor potential $\left(\Delta V_{\mathrm{T}}\right)$. Because cells were voltage clamped, predicted values of $\Delta V_{\mathrm{T}}$ associated with changes in $I_{\mathrm{T}}$ were defined as the shift in command voltage required to maintain the initial holding current that was observed at $V_{\text {Hold }}$ under resting conditions. As shown by the bottom panels in Figure $5 A, \Delta V_{\mathrm{T}}$ increased in proportion with $I_{\mathrm{T}}$ and, as predicted by ohmic behavior, rose asymptotically toward a maximal value equivalent to the available driving force $\left(\mathrm{DF}=V_{\mathrm{Hold}}-E_{\mathrm{T}}\right.$, where $E_{\mathrm{T}}$, the $I_{\mathrm{T}}$ reversal potential, was $-25.3 \mathrm{mV}$ (Fig. $1 B$ ). Indeed, concurrent changes in $\Delta V_{\mathrm{T}}$ and $I_{\mathrm{T}}$ were well fit by the equation $\Delta V_{\mathrm{T}}=I_{\mathrm{T}} /\left[a+\left(b \times \mathrm{I}_{\mathrm{T}}\right)\right]$, where $a$ is the baseline value of conductance and $b$ is the reciprocal of the driving force (i.e., 1/DF; i.e., 0.0288 $\left.\mathrm{mV}^{-1}\right)$. Moreover, slopes of linear regression fits of $\Delta V_{\mathrm{T}}$ versus $\log \left(I_{\mathrm{T}}\right)$ (to linearize the data) were not significantly different in cells treated with hypertonicity $\left(10.1 \pm 2.2, r^{2}=0.484\right)$ or suction $\left(14.7 \pm 12.0, r^{2}=0.669, p=0.118\right.$; Fig. $5 B)$.

Finally, we compared the relation between $\Delta V_{\mathrm{T}}$ and changes in action potential firing rate $(\Delta \mathrm{FR})$ in separate groups of OVLT neurons recorded under whole-cell current-clamp conditions. As illustrated in Figure 6, $A$ and $B$, equivalent and proportional relations were observed between $\Delta \mathrm{FR}$ and $\Delta V_{\mathrm{T}}$ when shrinking was evoked by hypertonicity or by pipette suction. Indeed, slopes of linear relations fitted through the two sets of data were not significantly different from one another (hypertonicity, $0.31 \pm 0.03 \mathrm{~Hz} / \mathrm{mV}, n=$ 10 ; suction, $0.34 \pm 0.05 \mathrm{~Hz} / \mathrm{mV}, n=4$, $p=0.66$; Fig. $6 C, D)$.

\section{Osmotic and mechanical sensing involves $\operatorname{Tr} p v 1$, not $\operatorname{Tr} p v 4$}

We previously reported that hypertonicity sensing in OVLT neurons requires expression of the Trpv1 gene (Ciura and Bourque, 2006). However it remains unknown whether $\operatorname{Trpv} 1$ is also required for mechanical excitation and whether Trpv4 plays any role in either the osmotic or mechanical control of these neurons. We therefore examined the responses of OVLT neurons isolated from WT mice and from animals lacking expression of $\operatorname{Tr} p v 1\left(\operatorname{Tr} p v 1^{-/-}\right)$or $\operatorname{Tr} p v 4\left(\operatorname{Tr} p v 4^{-/-}\right)$. As reported previously, we found that OVLT neurons isolated from $\operatorname{Tr} p v 1^{-/-}$ mice failed to show significant increases in conductance in response to hypertonic stimulation relative to baseline $(+25 \mathrm{mosmol} / \mathrm{kg},+0.01 \pm 0.04 \mathrm{nS}, p=$ 0.73, $n=23$; Fig. $7 A, B)$. In contrast, hypertonicity-treated OVLT neurons obtained from $\operatorname{Trp} v 4^{-1-}$ animals generated significant increases in conductance relative to baseline $(+0.34 \pm 0.14 \mathrm{nS}, n=16, p=0.032)$, and these changes were equivalent to those observed in WT OVLT neurons $(+0.56 \pm 0.07 \mathrm{nS}, n=87, p=0.492$ vs WT by one-way ANOVA and Tukey test). Similarly, we found that OVLT neurons isolated from $\operatorname{Trpv1} 1^{-1-}$ animals lacked responses to suction-evoked shrinking relative to baseline $(+.01 \pm 0.040 \mathrm{nS}, n=12, p=0.9$; Fig. $7 C, D)$, whereas significant responses were observed in both $\mathrm{WT}(+0.72 \pm 0.20 \mathrm{nS}, n=32, p=0.001)$ and $\operatorname{Tr} p v 4^{-/-}$animals $(+0.43 \pm 0.11 \mathrm{nS}, n=13, p=0.008)$. To confirm that the loss of responses to hypertonicity and suction in $\operatorname{Trp} v 1^{-/-}$OVLT neurons was due to the absence of a channel encoded by Trp 1 rather than a secondary consequence of gene deletion affecting the entire organism, we examined the effect of acutely treating WT neurons with SB366791, a selective inhibitor of TRPV1 channels (Gunthorpe et al., 2004). As shown in Figure 7, bath application 

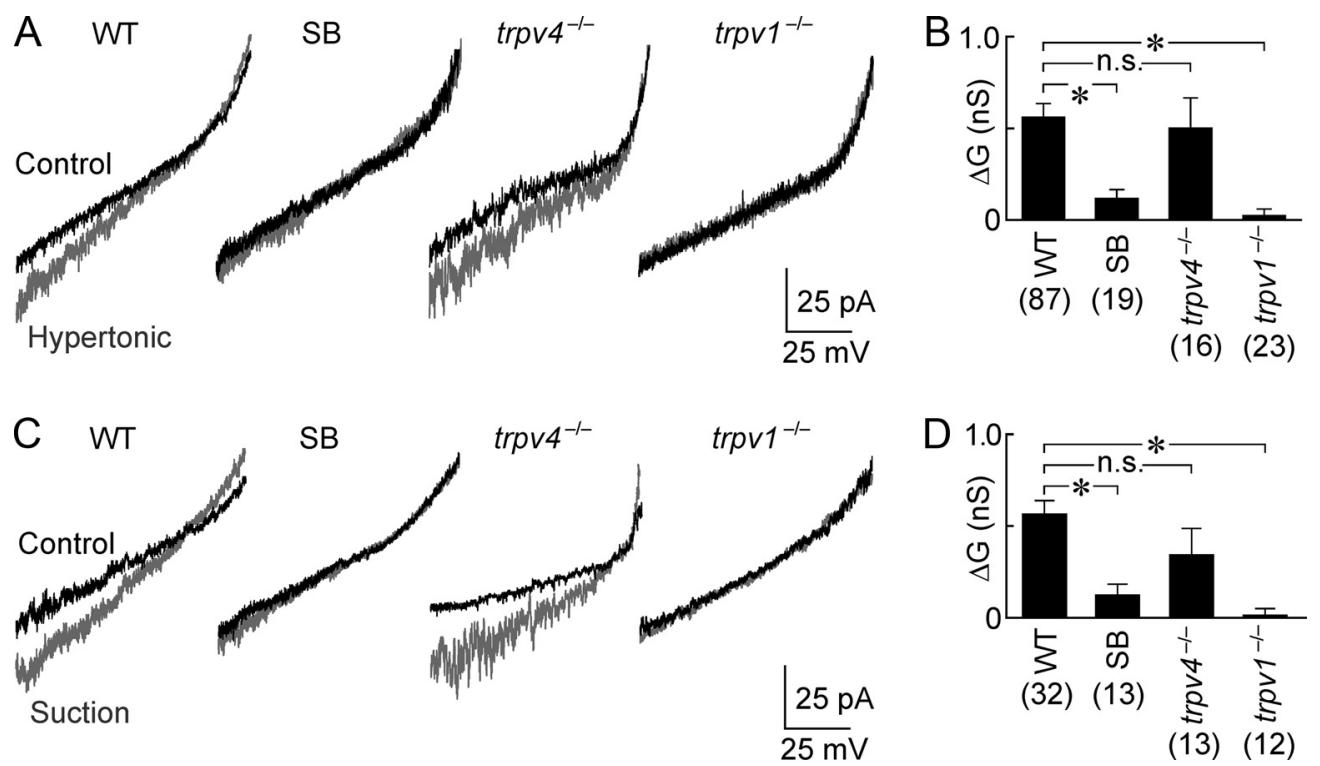

Figure 7. Intrinsic responses to osmotic and mechanical stimuli require Trpv 1 but not Trpv4. Voltage-clamp recordings in isolated OVLT neurons. $A$. Representative current-voltage relationships during control (black) and hypertonic stimulation (gray, +25 mosmol/kg) showing increases in conductance (slope) in OVLT neurons taken from WT (far left) and Trpv ${ }^{-/-}$mice (third from left). OVLT neurons from Trpv1 ${ }^{-1-}$ animals (far right) and WT neurons treated with SB366791 (SB, second panel from left) do not show any significant increase in conductance with hypertonic stimulation. B. Quantification of the maximal conductance changes $(\Delta G)$ observed in all conditions (numbers in parentheses indicate sample size for each group). $C$, Representative $I-V$ s of OVLT neurons from WT, SB-treated WT, Trpv4 ${ }^{-/-}$, and $\operatorname{Trpv} 1^{-/-}$showing the effects pipette suction causing an equivalent degree of shrinking. $\boldsymbol{D}$, Quantification of suction-evoked $\Delta \mathrm{G}$ in all conditions. In $\boldsymbol{B}$ and $\boldsymbol{D},{ }^{*} p<0.05$ and $n . s$. denotes not statistically significant $(p>0.05)$ as determined by one-way ANOVA/post hoc Tukey's test. Numbers in brackets indicate sample size for each group.

of $3 \mu \mathrm{M} \mathrm{SB} 366791$ prevented the increases in membrane conductance evoked by both hyperosmolality $(+0.12 \pm 0.06 \mathrm{nS}, n=19$, $p=0.06)$ and suction $(+0.07 \pm 0.12 \mathrm{nS}, n=13, p=0.55)$. Osmotically and mechanically evoked decreases in cell volume were equivalent in all groups (data not shown).

\section{Discussion}

Previous work has established that the OVLT serves as the brain's primary osmoreceptor area (Ramsay et al., 1983) and that neurons in this nucleus transduce hyperosmotic conditions into proportional increases in action potential firing rate (Ciura and Bourque, 2006). The information encoded by the electrical activity of these neurons is then relayed synaptically to diverse subsets of homeostatic effector neurons that induce appropriate osmoregulatory responses such as thirst, natriuresis, and antidiuretic hormone release (Denton et al., 1996; McKinley et al., 2006; Johnson, 2007; Bourque, 2008; Hollis et al., 2008). Interestingly, peripheral osmoreceptors located in the hepatoportal area are capable of detecting postingestion salt and water loads and modulating central osmoregulatory responses (Baertschi and Vallet, 1981; Choi-Kwon and Baertschi, 1991; McHugh et al., 2010; Lechner et al., 2011). It is presently unclear whether these peripheral receptors communicate independently with central effector neurons or if they modulate OVLT neurons via synaptic inputs (Bourque, 2008). Moreover, it is not known whether such receptors contribute significantly to the detection of systemic osmotic perturbations resulting from noningestive causes such as water loss through breathing, sweat, or diarrhea. The findings reported in our study reveal for the first time that hypertonicity can mediate a proportional excitation of the brain's primary osmoreceptor neurons via the cell-autonomous and mechanical modulation of nonselective cation channels encoded by $\operatorname{Trp} v 1$ and, surprisingly, that the Trpv 4 gene is not required for this process. Although our experiments were performed exclusively on acutely isolated OVLT neurons to facilitate volume measurements and to remove extrinsic influences, pre- liminary results show that osmotic and mechanically induced cell shrinking can also depolarize and excite OVLT neurons recorded during visualized whole-cell patch-clamp recordings in hypothalamic slices.

\section{Hypertonicity sensing is a mechanical process}

Early physiological studies suggested that the mammalian brain detects systemic hypertonicity through a process involving cellular dehydration because hyperosmolality induced by the addition of membrane permeant solutes that do not cause shrinking (e.g., urea) failed to elicit osmoregulatory responses (Gilman, 1937; Verney, 1947; McKinley et al., 1978; Ramsay et al., 1983). Although these findings indicated that extraction of cellular water is a requirement for hypertonicity sensing, they did not reveal whether this process specifically requires shrinking or a concentration of solutes in the cytoplasm. Indeed, recent work has shown that many types of ion channels can be modulated by changes in ionic strength (Nilius et al., 2000) or by the concentration of intracellular solutes such as $\mathrm{Ca}^{2+}$, phosphoinositides, or cyclic nucleotides (Cukkemane et al., 2011). Moreover, many types of cells are endowed with mechanisms that allow cell volume to recover within seconds after the onset of osmotic shrinking (Strange, 2004; Lang, 2007), an effect that could limit the usefulness of shrinking as an osmosensing signal. Our data provide the first evidence showing that OVLT neurons behave as near-perfect osmometers. Indeed, OVLT neurons displayed sustained and graded decreases in volume in response to hypertonic stimuli lasting up to an hour, a period of time exceeding normal delays for volume regulation in other cells and that is sufficient to mediate osmoregulatory responses under physiological conditions (e.g., exercise; Saat et al., 2005). The basis for the absence of regulatory volume increase in OVLT neurons exposed to mild hyperosmolality ( $<40 \mathrm{mosmol} / \mathrm{kg})$ remains to be determined, and our findings do not rule out the possibility of volume regulation in response to larger (nonphysiological) stimuli. 
The expression of osmometry in OVLT neurons was consistent with the possibility that these cells may use a mechanical process to transduce osmotic perturbations. However, this observation alone did not rule out a possible role for intracellular solute concentration during osmosensory transduction. Our findings provide three lines of evidence indicating that hypertonicity sensing by OVLT neurons is in fact mediated mainly by a mechanical effect of shrinking. First, activation of the transduction cascade under hypertonic conditions could be reversed by restoring cell volume with intracellular saline. Second, direct reduction of cell volume by aspiration of cytoplasm could activate excitatory responses in the absence of changes in internal solute concentration. Third, each of four steps linking cellular shrinking to increased action potential firing were found to be quantitatively equivalent whether shrinking was induced by hypertonicity or by the application of suction under isotonic conditions. Together, these results provide strong evidence indicating that the mechanical effect of the osmotically induced volume change is both necessary and sufficient to induce the proportional excitatory effect of hypertonicity in OVLT neurons.

\section{Osmomechanical sensing requires $\operatorname{Trpv} 1$}

Previous studies have shown that OVLT neurons can be labeled with antibodies directed against TRPV1 (Hollis et al., 2008) and that hypertonicity sensing is abolished in neurons isolated from the OVLT of Trpv1 $1^{-1-}$ mice (Ciura and Bourque, 2006). In agreement with these observations, $\operatorname{Tr} p v 1^{-/-}$mice are chronically hyperosmolar and show impaired water intake and antidiuretic hormone release in response to intraperitoneal injections of hypertonic saline (Ciura and Bourque, 2006; Sharif Naeini et al., 2006). A recent study failed to detect deficits in water intake or Fos expression in the OVLT of Trpv1 $1^{-/-}$mice injected with hypertonic saline (Taylor et al., 2008). However, important differences in experimental protocols could explain the different water intake profiles reported in these studies, Moreover, Fos expression in the OVLT is known to be stimulated by hypovolemia (McKinley et al., 2008) and hypernatremia (Hiyama et al., 2010), conditions that occur in concert with hypertonicity following injections of hypertonic saline and are detected by distinct sensory systems (Johnson et al., 1996; Hiyama et al., 2002). Finally, as mentioned earlier, noncell autonomous mechanisms, such as contributions from peripheral osmoreceptors, could also participate in the osmotic control of the firing rate of OVLT neurons in vivo. Thus, the presence of a Fos response in the OVLT of $\operatorname{Trp} v 1^{-/-}$mice injected with hypertonicity does not argue against the involvement of $\operatorname{Tr} p v 1$ in the intrinsic osmosensitivity of OVLT neurons. Indeed, our experiments specifically examined the responses of OVLT neurons to mechanical and osmotically induced shrinking in the absence of extrinsic influences. Our results provide unequivocal evidence showing that WT OVLT neurons can be excited by an intrinsic, shrinking-induced activation of nonselective cation channels. Our results also show that both types of responses are abrogated in OVLT neurons obtained from $\operatorname{Trp} v 1^{-1-}$ animals. Moreover, in WT neurons responses induced by both types of stimuli were eliminated by bath application of SB366791, a selective blocker of current flux through TRPV1 channels (Gunthorpe et al., 2004). These results provide conclusive evidence showing that $\operatorname{Tr} p v 1$ encodes a mechanically regulated channel that confers intrinsic osmosensitivity to OVLT neurons.

Interestingly, a recent study using mice engineered to express lacZ and placental alkaline phosphatase as reporters of trp 1 transcription failed to confirm expression of the trpv1 gene in the
OVLT and supraoptic nucleus (Cavanaugh et al.). However, our laboratory has detected mRNA coding for trpv1 RT-PCR analysis of tissue samples extracted from these brain areas (Sharif Naeini et al., 2006 and our unpublished observations), and specific antiTRPV1 immunolabeling has been detected in neurons from both regions (Sharif Naeini et al., 2006; Hollis et al., 2008). Unpublished studies from our laboratory indicate that immunolabeling of OVLT and supraoptic nucleus neurons using anti-trpv1 antibodies yields much weaker signals than those observed in dorsal root ganglion neurons. The negative results obtained by $\mathrm{Ca}-$ vanaugh et al. (2011) using gene reporter approaches could therefore have been caused by a lack of sensitivity to weak signals or by differences in transcriptional control associated with the variant of Trpv1 expressed in these areas. Indeed, although our data indicates that the Trpv1 gene encodes a hypertonicityactivated cation channel in OVLT neurons, other cells expressing wild-type TRPV1 protein (e.g., dorsal root ganglion neurons) appear to be insensitive to hypertonicity (Sudbury et al., 2010). Conversely, in contrast to cells that express wild-type TRPV1 protein (i.e., the capsaicin receptor) (Caterina et al., 1997), OVLT neurons from WT animals are insensitive to capsaicin (Ciura and Bourque, 2006). These observations suggest that OVLT neurons, like those in the supraoptic nucleus (Sharif Naeini et al., 2006), may express a variant of the TRPV1 channel that enables osmosensing but lacks motifs required to mediate responsiveness to capsaicin. Another possibility is that the native osmosensory channel comprises both WT TRPV1 and accessory subunits that enable osmosensing but somehow prevent capsaicin-mediated activation. Further studies are required to identify the nature of the osmosensory channel and the structure of the Trpv1 product expressed in OVLT neurons.

Previous work has shown that Trpv4 is also expressed in the OVLT (Liedtke et al., 2000), and Trpv4 ${ }^{-\prime-}$ mice show defects in systemic osmoregulation (Liedtke and Friedman, 2003; Mizuno et al., 2003). Since Trpv4 expression is not required for the activation of intrinsic cation channels upon exposure to hypertonicity, these observations suggest that additional Trpv4-dependent factors are involved in the central control of osmoregulation. As mentioned earlier, recent studies have shown that Trpv4 is required for hypotonicity sensing by peripheral osmoreceptors (McHugh et al., 2010; Lechner et al., 2011). It remains to be determined whether the influence of extrinsic Trpv4-dependent mechanisms on the central control of osmoregulation is mediated through changes in the firing of OVLT neurons or via other pathways.

\section{References}

Baertschi AJ, Vallet PG (1981) Osmosensitivity of the hepatic portal vein area and vasopressin release in rats. J Physiol 315:217-230.

Birder LA, Nakamura Y, Kiss S, Nealen ML, Barrick S, Kanai AJ, Wang E, Ruiz G, De Groat WC, Apodaca G, Watkins S, Caterina MJ (2002) Altered urinary bladder function in mice lacking the vanilloid receptor TRPV1. Nat Neurosci 5:856-860.

Bourque CW (2008) Central mechanisms of osmosensation and systemic osmoregulation. Nat Rev Neurosci 9:519-531.

Brooks VL, Qi Y, O’Donaughy TL (2005) Increased osmolality of conscious water-deprived rats supports arterial pressure and sympathetic activity via a brain action. Am J Physiol Regul Integr Comp Physiol 288:R1248-R1255.

Caterina MJ, Schumacher MA, Tominaga M, Rosen TA, Levine JD, Julius D (1997) The capsaicin receptor: a heat-activated ion channel in the pain pathway. Nature 389:816-824.

Cavanaugh DJ, Chesler AT, Jackson AC, Sigal YM, Yamanaka H, Grant R, O’Donnell D, Nicoll RA, Shah NM, Julius D, Basbaum AI. (2011) Trpv1 reporter mice reveal highly restricted brain distribution and functional expression in arteriolar smooth muscle cells. J Neurosci 31:5067-5077. 
Choi-Kwon S, Baertschi AJ (1991) Splanchnic osmosensation and vasopressin: mechanisms and neural pathways. Am J Physiol 261:E18-E25.

Ciura S, Bourque CW (2006) Transient receptor potential vanilloid 1 is required for intrinsic osmoreception in organum vasculosum lamina terminalis neurons and for normal thirst responses to systemic hyperosmolality. J Neurosci 26:9069-9075.

Cukkemane A, Seifert R, Kaupp UB (2011) Cooperative and uncooperative cyclic-nucleotide-gated ion channels. Trends Biochem Sci 36:55-64.

Denton DA, McKinley MJ, Weisinger RS (1996) Hypothalamic integration of body fluid regulation. Proc Natl Acad Sci U S A 93:7397-7404.

Gilman A (1937) The relation between blood osmotic pressure, fluid distribution and voluntary water intake. Am J Physiol 120:323-328.

Gunthorpe MJ, Rami HK, Jerman JC, Smart D, Gill CH, Soffin EM, Luis Hannan S, Lappin SC, Egerton J, Smith GD, Worby A, Howett L, Owen D, Nasir S, Davies CH, Thompson M, Wyman PA, Randall AD, Davis JB (2004) Identification and characterisation of SB-366791, a potent and selective vanilloid receptor (VR1/TRPV1) antagonist. Neuropharmacology 46:133-149.

Hiyama TY, Watanabe E, Ono K, Inenaga K, Tamkun MM, Yoshida S, Noda M (2002) $\mathrm{Na}(\mathrm{x})$ channel involved in CNS sodium-level sensing. Nat Neurosci 5:511-512.

Hiyama TY, Matsuda S, Fujikawa A, Matsumoto M, Watanabe E, Kajiwara H, Niimura F, Noda M (2010) Autoimmunity to the sodium-level sensor in the brain causes essential hypernatremia. Neuron 66:508-522.

Hollis JH, McKinley MJ, D’Souza M, Kampe J, Oldfield BJ (2008) The trajectory of sensory pathways from the lamina terminalis to the insular and cingulate cortex; a neuroanatomical framework for the generation of thirst. Am J Physiol Regul Integr Comp Physiol 294:R1390-R1401.

Honda K, Negoro H, Dyball RE, Higuchi T, Takano S (1990) The osmoreceptor complex in the rat: evidence for interactions between the supraoptic and other diencephalic nuclei. J Physiol 431:225-241.

Johnson AK (2007) The sensory psychobiology of thirst and salt appetite. Med Sci Sports Exerc 39:1388-1400.

Johnson AK, Gross PM (1993) Sensory circumventricular organs and brain homeostatic pathways. FASEB J 7:678-686.

Johnson AK, Cunningham JT, Thunhorst RL (1996) Integrative role of the lamina terminalis in the regulation of cardiovascular and body fluid homeostasis. Clin Exp Pharmacol Physiol 23:183-191.

Lang F (2007) Mechanisms and significance of cell volume regulation. J Am Coll Nutr 26:613S-623S.

Lechner SG, Markworth S, Poole K, Smith ES, Lapatsina L, Frahm S, May M, Pischke S, Suzuki M, Ibañez-Tallon I, Luft FC, Jordan J, Lewin GR (2011) The molecular and cellular identity of peripheral osmoreceptors. Neuron 69:332-344

Liedtke W (2007) Role of TRPV ion channels in sensory transduction of osmotic stimuli in mammals. Exp Physiol 92:507-512.

Liedtke W, Friedman JM (2003) Abnormal osmotic regulation in trpv4 $4^{-1-}$ mice. Proc Natl Acad Sci U S A 100:13698-13703.

Liedtke W, Choe Y, Martí-Renom MA, Bell AM, Denis CS, Sali A, Hudspeth AJ, Friedman JM, Heller S (2000) Vanilloid receptor-related osmotically activated channel (VR-OAC), a candidate vertebrate osmoreceptor. Cell 103:525-535.

McHugh J, Keller NR, Appalsamy M, Thomas SA, Raj SR, Diedrich A, Biaggioni I, Jordan J, Robertson D (2010) Portal osmopressor mechanism linked to transient receptor potential vanilloid 4 and blood pressure control. Hypertension 55:1438-1443.
McKinley MJ, Denton DA, Weisinger RS (1978) Sensors for antidiuresis and thirst-osmoreceptors or CSF sodium detectors? Brain Res 141:89103.

McKinley MJ, Denton DA, Oldfield BJ, De Oliveira LB, Mathai ML (2006) Water intake and the neural correlates of the consciousness of thirst. Semin Nephrol 26:249-257.

McKinley MJ, Walker LL, Alexiou T, Allen AM, Campbell DJ, Di Nicolantonio R, Oldfield BJ, Denton DA (2008) Osmoregulatory fluid intake but not hypovolemic thirst is intact in mice lacking angiotensin. Am J Physiol Regul Integr Comp Physiol 294:R1533-R1543.

Mizuno A, Matsumoto N, Imai M, Suzuki M (2003) Impaired osmotic sensation in mice lacking TRPV4. Am J Physiol Cell Physiol 285:C96-C101.

Nilius B, Eggermont J, Droogmans G (2000) The endothelial volumeregulated anion channel, VRAC. Cell Physiol Biochem 10:313-320.

Ramsay DJ, Thrasher TN, Keil LC (1983) The organum vasculosum laminae terminalis: a critical area for osmoreception. Prog Brain Res 60:91-98.

Richard D, Bourque CW (1995) Synaptic control of rat supraoptic neurones during osmotic stimulation of the organum vasculosum lamina terminalis in vitro. J Physiol 489:567-577.

Saat M, Sirisinghe RG, Singh R, Tochihara Y (2005) Effects of short-term exercise in the heat on thermoregulation, blood parameters, sweat secretion and sweat composition of tropic-dwelling subjects. J Physiol Anthropol Appl Human Sci 24:541-549.

Sayer RJ, Hubbard JI, Sirett NE (1984) Rat organum vasculosum laminae terminalis in vitro: responses to transmitters. Am J Physiol 247:R374R379.

Sharif Naeini R, Witty MF, Séguéla P, Bourque CW (2006) An N-terminal variant of Trpv1 channel is required for osmosensory transduction. Nat Neurosci 9:93-98.

Strange K (2004) Cellular volume homeostasis. Adv Physiol Educ 28:155-159.

Sudbury JR, Ciura S, Sharif-Naeini R, Bourque CW (2010) Osmotic and thermal control of magnocellular neurosecretory neurons-role of an $\mathrm{N}$-terminal variant of trpv1. Eur J Neurosci 32:2022-2030.

Taylor AC, McCarthy JJ, Stocker SD (2008) Mice lacking the transient receptor vanilloid potential 1 (TRPV1) channel display normal thirst responses and central Fos activation to hypernatremia. Am J Physiol Regul Integr Comp Physiol 294:R1285-R1293.

Thrasher TN, Keil LC, Ramsay DJ (1982) Lesions of the organum vasculosum of the lamina terminalis (OVLT) attenuate osmotically-induced drinking and vasopressin secretion in the dog. Endocrinology 110: 1837-1839.

Trudel E, Bourque CW (2010) Central clock excites vasopressin neurons by waking osmosensory afferents during late sleep. Nat Neurosci 13:467474.

Verney EB (1947) The antidiuretic hormone and the factors which determine its release. Proc R Soc Lond Ser B 135:25-106.

Vivas L, Chiaraviglio E, Carrer HF (1990) Rat organum vasculosum laminae terminalis in vitro: responses to changes in sodium concentration. Brain Res 519:294-300.

Zhang Z, Bourque CW (2003) Osmometry in osmosensory neurons. Nat Neurosci 6:1021-1022.

Zhang Z, Kindrat AN, Sharif-Naeini R, Bourque CW (2007) Actin filaments mediate mechanical gating during osmosensory transduction in rat supraoptic nucleus neurons. J Neurosci 27:4008-4013. 